\title{
Potential of dual-use policies to meet family planning and HIV prevention needs: a case study of Zimbabwe and Mozambique
}

\author{
Ndola Prata, Amita Sreenivas, Ben Bellows
}

\begin{abstract}
Background and methodology The fight against the HIV epidemic in many high-prevalence countries is a struggle to motivate culturally relevant risk reduction in general populations that have been educated to associate HIV risk with commercial sex, injection drug use and other stigmatised behaviours. Common concurrent partnerships, which facilitate transmission of HIV in many high-prevalence countries, are only beginning to receive the attention they deserve. This has made the promotion of dual-use methods, such as condoms, for individuals who require both HIV protection and contraception very difficult. Recent research on concurrent partnerships and the implications for high HIV risk in sexually networked but sexually modest general populations is forcing another assessment of the response to HIV. In the light of the epidemic, it is important to better understand which policies will better meet HIV prevention and family planning (FP) needs. This article explores the potential of dual-use policies by examining Zimbabwe and Mozambique.
\end{abstract}

Results Zimbabwe, with a vertically driven, stronger FP programme predating the HIV epidemic, has not yet seen an increase in condom use to the level desired by their moderately strong HIV prevention programme - one that has adopted a primarily single-use condom policy.

\section{Introduction}

The fight against the HIV epidemic in many highprevalence countries is a struggle to motivate culturally relevant risk reduction in general populations that have been educated to associate HIV risk with commercial sex, injecting drug use and other stigmatised behaviours. Common concurrent partnerships that facilitate transmission of HIV in many high-prevalence countries are only beginning to receive the attention they deserve. ${ }^{1}$ This has made the promotion of dual-use methods, such as condoms, for individuals who require both HIV protection and contraception very difficult. Furthermore, recent research on concurrent partnerships and the implications for high HIV risk in sexually networked but sexually modest general populations is forcing another assessment of the response to HIV. ${ }^{1}$ In light of the epidemic, it is important to better understand which policies will better meet HIV prevention and family planning (FP) needs. This article explores the potential of dual-use policies by

School of Public Health, University of California, Berkeley, CA, USA

Ndola Prata, MD, MSc, Associate Professor

Amita Sreenivas, MPH, Associate Specialist

Ben Bellows, MPH, Research Fellow

Correspondence to: Miss Amita Sreenivas, Bixby Program in Population, Family Planning and Maternal Health, Global Health, University Hall, School of Public Health, University of California-Berkeley, Berkeley, CA 94720-7360, USA.

E-mail: Sreenivas.Bixby@gmail.com
Mozambique, however, continues to have a much weaker FP programme, but is witnessing a significant increase in condom use driven by their strong HIV programme - one that is further integrated with FP content.

Discussion Integration of HIV and FP programmes has the potential to meet the need for HIV and pregnancy prevention more efficiently. By themselves, these programmes are unable to meet the need for condoms. The poorest of the poor are feeling the brunt of this inadequacy. Countries such as Zimbabwe and Mozambique have the potential to tremendously improve their efforts in increasing condom use. We suggest that thoughtful and detailed integration of HIV and FP programmes will work synergistically to reach common goals. Until a more promising method besides condoms is commercially available for protection against unintended pregnancy and sexually transmitted infections such as HIV, effective strategies must include dual-use policies as well as counselling on all available contraceptive methods so that women can maximise the benefits of mixing methods.

Keywords condoms, dual-use policies, family planning, HIV prevention, pregnancy prevention

J Fam Plann Reprod Health Care 2008; 34(4): 219-226

(Accepted 14 March 2008)

examining Zimbabwe and Mozambique - two countries hit heavily by HIV, but with very different FP and HIV prevention programmes. The performance of national efforts in FP and HIV prevention is reviewed to determine how programmes could become more successful in Zimbabwe, Mozambique and similar settings. We assess performance by examining international and national funding priorities, national HIV and FP efforts, and trends in contraceptive and HIV prevalence. In view of our findings, implications and recommendations are discussed.

\section{Global burden and unmet need}

As of 2006 there were an estimated 38 million individuals living with HIV globally, of whom over 4 million were newly infected. ${ }^{2}$ Sub-Saharan Africa (SSA) alone carried $63 \%$ of this burden. ${ }^{3}$ And although HIV prevalence globally appears to have plateaued, the number of individuals newly infected with HIV each year remains constant. ${ }^{2}$ In addition,

\section{Key message points} women is $25 \%$. Yet most FP and HIV programmes fail to acknowledge the role which sexual activity plays in Condom dual-use policies have the potential to significantly reduce HIV/STI infection and unintended

Zimbabwe and Mozambique could significantly increase condom use by capitalising on stronger integration of HIV and FP programmes. 
the unmet need for contraceptives among women who are HIV positive is a staggering $25 \% .{ }^{4}$ It is estimated that nearly $50 \%$ of pregnancies worldwide are unplanned and $25 \%$ are unwanted. Among those women who become pregnant, one in three will die due to complications during pregnancy or delivery. Within this group, more than one in four pregnant women will undergo a termination and $13 \%$, or nearly 74000 , will die because the procedure was done in unsafe conditions. ${ }^{5}$ This means that if the global need for FP was met, nearly 178000 women's lives could be saved each year. Additionally, the supply of condoms, the only widely available contraceptive method to offer dual protection against HIV and unwanted pregnancy, meets less than $50 \%$ of the global demand ${ }^{2}$. These numbers underscore the need for HIV prevention and FP services, numbers that cannot fall quickly without considerable examination and adoption of policies that are more effective.

It is well known that HIV prevention and control programmes have several areas of overlap with FP services. Strong joint policies and effective resource allocation have the potential to reduce mother-to-child transmission of HIV, help alleviate HIV orphan numbers, improve national labour supplies, and strengthen national security. 2,6,7 However, many policies, and therefore services, to date do not consider HIV prevention and FP under the same lens, and continue to narrowly view FP as the provision of contraceptives or a referral. ${ }^{8}$

Recently researchers have begun to acknowledge the importance of FP in the prevention of mother-to-child transmission (PMTCT) of HIV in unwanted pregnancies. A 2004 study analysing 14 high HIV prevalence countries demonstrated that 32000 HIV-positive births could be averted in the year 2007 by simply adding FP to PMTCT services. ${ }^{6,7}$ In a follow-up study, Reynolds et al. calculated that it was more cost effective to prevent an HIV-positive birth using FP versus a single-dose Nevirapine regime. ${ }^{6}$ Nevertheless, integrated FP services - those which include both HIV/sexually transmitted infection (STI) and pregnancy prevention under the same purview - are being sidelined by donor and government priorities towards more vertical programmes - those which address HIV/STI and pregnancy as separate problems. 2,9

Interestingly, however, research conducted by Ross and colleagues has shown that although the response to HIV has led to changes in donor priorities, personnel and logistics systems, there exists no compelling evidence that FP programme performance has suffered up to the year 2002.10 Instead, while HIV/AIDS programme effort has continued to increase, so has FP programme effort (FPE). ${ }^{11,12}$ Although Ross' research is encouraging, it does not examine the loss or gain in performance due to integrated and vertically driven policies.

\section{Single-use versus dual-use}

Single-use and dual-use policies related to the use of condoms for HIV prevention and/or fertility control are essential parts of vertical and integrated programmes, respectively. Under such policies condom use (less often other barrier methods) is marketed as protection against either HIV/STIs (single use, vertical policies) or both HIV/STIs and pregnancy (dual use, integrated policies). In the former case, vertically driven FP services have focused on more modern methods such as the pill or injectables.

There are many reasons for vertical programming. It is well known that condoms are associated with higher rates of discontinuation and failure for reasons including male partner objection, inconvenience, and being less effective than other contraceptive methods. ${ }^{13}$ Intrinsic to these attitudes are the stigma and sex inequality with which condoms are deeply connected. Condoms, a malecontrolled method, have traditionally been marketed towards high-risk populations and are now often associated with infidelity and illicit sex - offering protection against only disease. As a result, successful promotion has raised demand for condoms, but marketing campaigns have not been successful in increasing condom use inside of marriage or amongst young adults who are less likely to be concerned with infection risk. ${ }^{14,15}$ This is significant for regions with generalised heterosexual HIV epidemics, where the populations at risk of unwanted pregnancies and those at risk of HIV infection are often the same. ${ }^{16}$

However, research has shown that the promotion of condoms can aid in increasing perceived risk of HIV infection, reduce stigma, and maintain a woman's right to control her own fertility. ${ }^{13,17}$ An unpublished study reported by Gollub found that counselling women on their various prevention options had a substantial effect on increasing population protection because women chose to alternate or add on methods (e.g. male condom and diaphragm, male and female condoms). 17 To further examine the potential benefit dual-use policies could have on contraceptive and HIV prevalence we look at FP and HIV programme performance using two case studies: Zimbabwe and Mozambique.

\section{Case studies: Zimbabwe and Mozambique}

We conducted an extensive literature review that included pertinent financial reports, AIDS and FP programme effort analyses, epidemiological reports, and all available Demographic and Health Surveys (DHS) for each country. The two country case studies were chosen due to their different stages in FP programme maturity at the beginning of the HIV epidemic. In our analysis we map changes in international resource allocation since the 1990s, how successful policies and FP/HIV programmes have been during the era of HIV, and consequential changes in HIV and contraceptive prevalence. The evidence presented will be used to determine how programme efforts could become more successful in each country and in similar settings.

\section{Socioeconomic and demographic information}

Zimbabwe and Mozambique are both located in southeastern Africa. Zimbabwe, the smaller of the two nations, has a population of over 13 million with a moderately high total fertility rate (TFR) of 3.6 births per woman. Conversely, Mozambique has a population of over 20 million and has a much higher TFR of 5.5.18,19 According to the 2006 Human Development Index, both nations are considered at low human development, with a Gross Domestic Product (GDP) per capita of US\$2065 and US\$1237, and ranking 151 and 168 out of 177 nations, respectively. This is highlighted by devastatingly low life expectancies at birth: 37 years in Zimbabwe and only slightly higher at 42 years in Mozambique. ${ }^{19}$ These figures are due primarily to premature death caused by HIV. Today both countries rank amongst those nations with a generalised HIV epidemic, namely when HIV infects individuals outside of high-risk communities such as injecting drug users and commercial sex workers. In 2005, amongst those aged 15 to 49 years, $20 \%$ were living with HIV in Zimbabwe. In Mozambique, $16 \%$ were infected. ${ }^{19}$

\section{International and national priorities}

Population assistance to developing countries occurs through bilateral, multilateral and non-governmental channels. In 2004, the United Nations Population Fund (UNFPA) published its most recent report on financial resource flow from 1994 to 2004 for population activities 
(FP, general reproductive health, basic research, and HIV/STIs). As expected, the data show that overall, international assistance changed dramatically during the 10 -year period. Where in $1994 \mathrm{FP}$ activities were being supported by $55 \%$ of available global funds, they only obtained $9 \%$ in 2004. Conversely, in 1994, only $9 \%$ of global population health funding went to HIV/STI programmes. However, by 2004 such programmes were receiving 54\% of a much larger pool of available funding. It is important to note that these figures do not include the substantial increase in recent US government spending on HIV/AIDS under the President's Emergency Plan for AIDS Relief (PEPFAR) programme for 15 high HIV prevalence countries. Furthermore, although HIV/STI funds seem to be steadily increasing, resources available for FP services have been fluctuating tremendously year-to-year (albeit declining in the 10-year period), experiencing significant cuts between 1995 and 1996 as well as 2002 and 2003. ${ }^{20}$ According to the 2005 UNFPA report on donor support for FP resources, overall expenditure on condoms versus other contraceptive commodities does appear to be stable since 2000. ${ }^{21}$ However, contraceptive supplies continue to fall short of overall need for birth control and methods of HIV/STI protection. ${ }^{14,21}$

In SSA, the changes in funding priorities within national governments are not as drastic, but still significant. Within a 5-year period from 1997 and 2001-2002, government expenditures on FP services in SSA experienced a $14 \%$ drop: from $24 \%$ in 1997 to $10 \%$ since 1999. In SSA, UNFPA also noted a wide fluctuation in STIs/HIV resource allocation from $39 \%$ of population activities budget to $16 \%$ in 1998 , to $8 \%$ in $1999 / 2000$ and up to $62 \%$ in $2001 / 2002$. Overall, however, government expenditure in SSA for all of population activities (i.e. FP, HIV/STIs, general reproductive health and basic research) varies only slightly in 1997 (US\$62 538 000) compared to 2001/2002 (US\$64 599 000).22

In Zimbabwe and Mozambique, annual health expenditure per capita is only US\$132 and US\$45, respectively. ${ }^{19}$ Both countries rely heavily on international donors to support local health-related activities. To maintain population efforts in Zimbabwe and Mozambique, they were given a total of US\$47.6 million and US\$77.3 million, respectively, in 2003. This is substantially more than just 9 years earlier, when donors allocated only US\$7.7 million and US\$4.2 million, respectively. ${ }^{20}$ Funding specifically for condoms and other contraceptives ranged from US\$4.1 to US\$7.9 million in Zimbabwe and US\$2.1 to US\$6.8 million in Mozambique between 1992 and 2005,21,23 In Zimbabwe, however, due to the precarious political situation and failure to service its debt, many donors are withdrawing or reducing their involvement. ${ }^{24}$ In Mozambique, these figures do not include the more recent substantial PEPFAR funding it has been allotted for HIV programmes. Overall, this level of expenditure is still not enough to support contraceptive and HIV prevention needs in either nation.

In addition to overall contraceptive support it is important to examine the trends specific to condom support for both countries. Globally, donor support for condoms has been declining, when it needs to be increasing. Where in 1990 donors, including the United States Agency for International Development (USAID) and UNFPA, provided over 969 million condoms, they supplied only 951 million in $2000 .{ }^{14}$ In our case countries, the number of male condoms donated annually between 1996 and 2005, ranged from 22 to 47 million in Zimbabwe and 13 to 18 million in Mozambique. ${ }^{21,23}$ This may look like progress, but does not take population growth into account. Between
2001 and 2004, the average number of male and female condoms donated annually, per male aged 15 to 59 years, was only 33 in Zimbabwe and 8 in Mozambique. ${ }^{25}$

\section{National programme efforts}

Using the AIDS Programme Effort Index (API) as well as the FP Effort Index (FPE), the HIV and FP programmes in both case countries are examined to determine how well they have been reaching the HIV prevention and FP needs of their populations over the past several years.

\section{Programmes in Zimbabwe}

In 1953, modern FP services were introduced in Zimbabwe, followed by the establishment of the Family Planning Association of Rhodesia (FPAR) in 1965. After independence in 1980, Zimbabwe transformed FPAR into a parastatal under the Ministry of Health and Child Welfare, renaming it the Zimbabwe National Family Planning Council (ZNFPC). Today, the ZNFPC is responsible for guiding FP policy development as well as two nationwide service delivery programmes for contraceptive commodities: the Community-Based Distribution (CBD) programme and a small number of FP clinics. Currently, ZNFPC oversees more than 800 CBDs nationwide for the distribution of mainly oral contraceptive pills and condoms. ${ }^{26}$

With regard to HIV, the country's initial response, although seemingly rapid, focused primarily on surveillance and specific 'high-risk' populations. In 1985, Zimbabwe found their first case of HIV. Immediately following the discovery, the nation became one of the first globally to implement mandatory universal screening of blood products. Following the new initiative, Zimbabwe established the National AIDS Coordination Program (NACP) in 1987, followed by the implementation of HIV sentinel surveillance in 1991. Although the NACP was responsible for coordinating a national HIV/AIDS response, no formal policy was created until 1999 and implementation did not begin until the creation of the National AIDS Council (NAC) in May 2000. In light of the current political crisis it is difficult to determine how much of the NAC policy has been carried out. In January 2002, the government finally launched a formal PMTCT programme. ${ }^{24}$

\section{Programmes in Mozambique}

In 1980, the Mozambican government established a national FP programme. ${ }^{27}$ The programme, largely built around health worker training, was designed to integrate with the maternal and child health programme with the goal of reducing maternal and infant morbidity and mortality. ${ }^{28}$ In 1992, the 17 -year civil war ended, marking the beginning of a national consensus-building initiative known as the Agenda 2025 National Vision and Development Strategy Process. By 2000, former President Joaquim Chissano appointed a committee of civil and political leaders to address the implementation of issues deemed most important to his citizens; these issues included FP and the impact of HIV/AIDS on various sectors. The current President, Armando Emilio Guebuza, has promised to continue the policies. ${ }^{29.30}$ Contraceptive commodities have been delivered through both the public and private sector. It is mainly pills and injectables, however, which remain the most common deliverable from the government, while condoms are more often provided through private outlets. ${ }^{31}$

With regards to HIV, Mozambique's first case was reported in 1986. Interest in integration of HIV/AIDS with poverty reduction and economic development efforts has led to policies that connect multiple stakeholders as well as 
political consensus. Surveillance was a key part of Mozambique's initial response to HIV/AIDS, instituted in 1988 by the Ministry of Health at a single site (Maputo City). By 2001 there were 36 different sentinel sites, with at least one rural and one urban site for each province. The government has also maintained responsibility for screening blood products at all blood transfusion centres in the public sector. Many of the centres run by the private sector, however, remain unexamined. A national multi-sector HIV/AIDS strategic plan was also developed, followed by a second to address more recent issues from 2005 to 2009. In 2005, an operational plan was also produced. Between 2002 and 2005, PMTCT services expanded reaching 74 centres around the nation. The dissemination of information, education and communication materials regarding the virus has also been a key part of government plans. However, plans to address the needs of young people had not been written into policy as of 2005.32

\section{HIV and FP programme integration}

An analysis of FP content in HIV/AIDS, volunteer counselling and testing (VCT) and PMTCT policies among 16 high-prevalence HIV countries found major gaps in the integration of FP and HIV prevention services. The report states that often FP is only mentioned in guidelines suggesting FP clinics include HIV/STI counselling. Currently, HIV/AIDS policies in Zimbabwe and Mozambique do not detail FP and HIV programme integration.

Zimbabwe's HIV policy makes a brief reference to the importance of (1) condoms as a method of protection against HIV/STIs, cervical cancer and unwanted pregnancies and (2) information for individuals and couples considering pregnancy in view of HIV. ${ }^{8}$ One study found that nationallevel programme managers of PMTCT services do include FP services. However, the focus is on counselling HIVpositive women how to avoid unwanted pregnancy (by encouraging the use of injectables and other hormonal methods) rather than the primary prevention of HIV infection through the promotion of barrier methods. ${ }^{33}$ Information on the extent to which specific VCT guidelines mention FP could not be found in our analysis of the literature.

In Mozambique, VCT guidelines do mention FP, but only with respect to using condoms - emphasising they are for disease protection first and preventing unwanted pregnancies second. Information on all contraceptive methods available to women is not provided. Mozambican guidelines regarding vertical transmission of HIV are much more comprehensive, with particular emphasis on how women who are HIV-positive can avoid unwanted pregnancies (similar to Zimbabwe). Counsellors are encouraged to give women information on all available contraceptives as well as promote the use of barriermethods (mainly condoms) to prevent further infection. ${ }^{8}$

\section{National programme effort in population activities}

To determine how well Zimbabwe and Mozambique have been reaching the HIV prevention and FP needs of their populations, HIV and FP programme performance in both case countries will be examined using standardised indicators.

Since its inception, the ZNFPC CBD programme made significant and well-documented contributions to FP in Zimbabwe. However, an assessment of the CBD programme indicates that it suffered a slight decline in effectiveness in the late 1990s and early 2000s, partly due to its focus on older, married women and through being a vertically driven programme (where condom education has been considered a responsibility of the government's HIV programme). ${ }^{26}$ Thus, although CBDs were created to supply clients with oral contraceptive pills (OCP) and condoms, the focus has always been on providing OCP. The educators who formed the basis for CBDs are in fact known as "pill agents" by the Ministry of Health. As expected, $90 \%$ of Zimbabwean women who are using OCP use brands that are distributed by the public sector. The social marketing of condoms remains the responsibility of mainly non-governmental organisations. The 2005-2006 DHS found that $83 \%$ of men who use condoms obtain them from the private sector. 34

Zimbabwe's efforts in HIV have been weaker than its efforts in FP. Whereas the CBDs have been able to reach a wide percentage of the Zimbabwean population, HIV services have been segregated, stigmatised, and largely unsuccessful in reaching the general population. The 2006 Global Report, for example, indicates that Zimbabwe's recent decline in HIV prevalence is largely due to a reduction in sexual partners. However, efforts remain focused on high-risk groups rather than young adults and married heterosexual couples who are at higher risk in this population. One report found that the government has "failed to adopt laws and policies that ensure young people the right to access the information and methods to protect themselves from unwanted pregnancy and HIV/STIs ... . As a result, health workers have tended to turn away adolescents seeking dual protection information and services". 24 Forty percent of Zimbabweans are under the age of 15 years and likely to be missed by narrowly operationalised HIV services. The same report also reminds policymakers that in a country where $14 \%$ of adults reported being in a polygamous union, programmes do not readily address the dual reproductive health needs of younger wives who are at an increased risk of HIV infection. ${ }^{24}$ Furthermore, although there is some connection between FP and HIV prevention through the newly launched PMTCT programme, the integration is weak as it is not available in all existing maternity units and, more importantly, completely misses the $68 \%$ of women who deliver at home..$^{24,34}$

FP efforts in Mozambique have not been as successful as those in Zimbabwe. Although programmes and policies have been ambitious in directing attention towards unmet need, services through the public sector have suffered major growth constraints due to poor healthcare infrastructure and lack of sufficiently trained health personnel. ${ }^{28} \mathrm{OCP}$, for example are primarily accessed through the public sector $(78 \%)$, whereas condoms are primarily procured from private 'outlets' [e.g. mainly partners $(42 \%)$, friends $(8 \%)$, pharmacies $(7 \%)$ or condom booths $(6 \%)$ ]. ${ }^{31}$ Furthermore, condom promotion appears to be the main responsibility of the nation's efforts in HIV/AIDS, socially marketed as a method of disease protection first. 8

There are remaining challenges in Mozambique's efforts to reduce the impact of HIV. Although the government has seemingly placed more importance on addressing adolescents, PMTCT, and marketing condoms than in Zimbabwe, the nation's HIV activities have been sidelined by other priorities. For example, research shows that more than $50 \%$ of adolescents have had sex by the time they are 16 years old. ${ }^{32}$ This is significant, as nearly $50 \%$ of the population is aged between 10 and 24 years. ${ }^{31}$ However, as mentioned above, policies regarding youth HIV education have not been written. Additionally, although PMTCT services have been growing, only $4.9 \%$ of mothers and $3.2 \%$ of infants in need of assistance during the first 9 months of 2005 received prophylaxis. This is in 


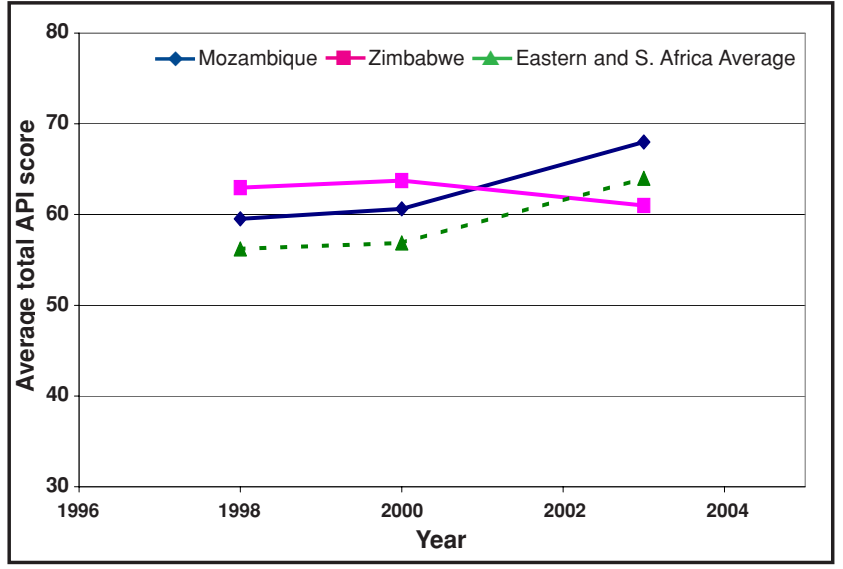

Figure 1 Trends in AIDS Program Effort Index (API), 1998-2003. Source: USAID, UNAIDS, POLICY Project ${ }^{11}$

large part due to the concentration of efforts in the central region, while prevention activities are not reaching remote rural areas, which account for 13 million of Mozambique's population. One of the main reasons for this continues to be the lack of available and much needed human resources. 32

To assess national HIV/AIDS and FP performance more formally, we use the API and FPE indices. The API is made up of 10 components: political support, policy formulations, organisational structure, programme resources, evaluation and research, legal and regulatory aspects, human rights, prevention programmes, care programmes, and service availability. 11 Figure 1 shows trends in API from 1998 to 2003 for both case countries in comparison to Eastern and Southern Africa. [NB. Countries are categorised as having a weak AIDS programme if the overall score is $36-50$, moderate is $51-60$, strong is $61-69$ and very strong is $70-82.]^{11}$ Comparing country-specific scores to the Eastern and Southern Africa region, we observe that until 2000 both countries' AIDS programmes scored above the regional average, and Mozambique continued to do so in 2003, while Zimbabwe's score slipped below the regional average. Zimbabwe experienced a slight decrease in API from 63 to 61, but is still considered to have a relatively strong AIDS programme. This decline is mostly in the components related to prevention programmes (very strong to weak) and organisational structure (strong to weak). Conversely, the Mozambique AIDS programme registered an increase in API, from 60 to 68 (moderate to strong). Almost all components increased their score, but the largest improvements were those in prevention efforts (moderate to very strong). ${ }^{11}$

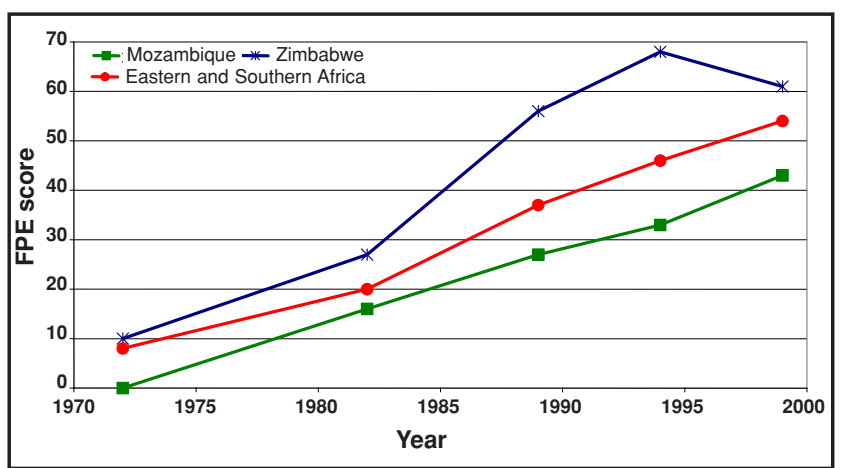

Figure 2 Family Planning Program Effort (FPE) scores, 1972-1999. Source: The Family Planning Program Effort Index: 1999 Cycle $^{35}$

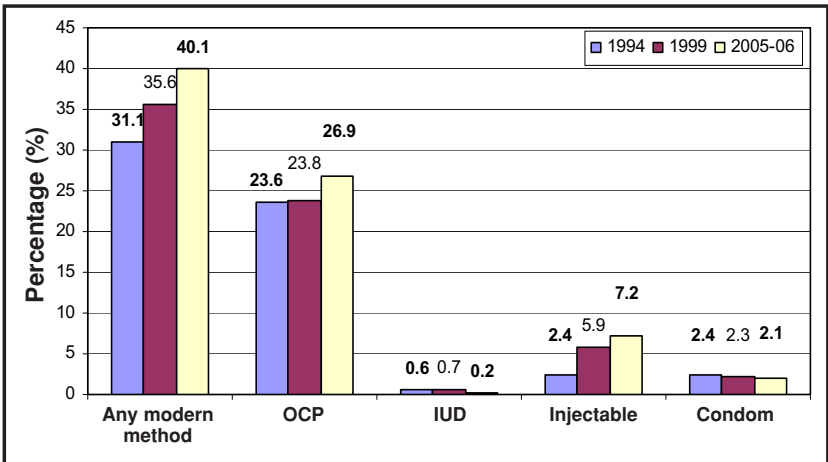

Figure 3 Current use of contraceptive methods in Zimbabwe, 1994-2006. Source: Zimbabwe Demographic and Health Survey (DHS) for 199437, $1999^{38}$ and 2005-2006 ${ }^{34}$ (Macro International Inc.). OCP, oral contraceptive pill; IUD, intrauterine device

To assess FP performance, the FPE examines 30 programme features that fall under national policy, services, evaluations, and method availability. Available data follows countries from 1972 until 1999.35 Figure 2 presents trends in FPE scores for Mozambique, Zimbabwe and the Eastern and Southern Africa regional average. According to FPE index, Zimbabwe saw its FPE peak as a strong programme in 1994 (score 68). [NB. Countries are categorised as having a very weak or non-existent FP programme if the overall score is $0-20$, weak is $21-45$, moderate is 46-66 and strong is $67+.]^{35}$ In 1999, the FPE fell to moderate (score 61), even though still above the regional average. The two components that significantly reduced its scores were 'policy' and 'services'. Conversely, Mozambique's efforts were considered weak in 1999 (score 43). However, this is a significant improvement from scores of 0 in 1972, 16 in 1982, 27 in 1989 and 33 in 1994. In the past few decades, all FPE components registered improvements, with the most significant change in the 'evaluation' component (weak to moderate). 35 The trends in API and FPE scores for Mozambique and Zimbabwe underscore the strengths each nation has to offer its programme efforts as well as the potential for significant improvement.

\section{Trends in contraceptive and HIV prevalence}

Using available DHSs for Zimbabwe and Mozambique, trends in contraceptive and HIV prevalence are examined to determine how current policies are affecting their populations. Overall, ever use of modern methods in Zimbabwe has increased, giving it one of the highest contraceptive prevalences in SSA. As discussed above, the FP programme in Zimbabwe relies entirely on OCP, even though the overall OCP contribution to contraceptive prevalence has been decreasing over time ( $86 \%$ in 1988 to $57 \%$ in 2005-2006). 34,36 The use of injectables has been gradually increasing over time and now accounts for $32 \%$ of

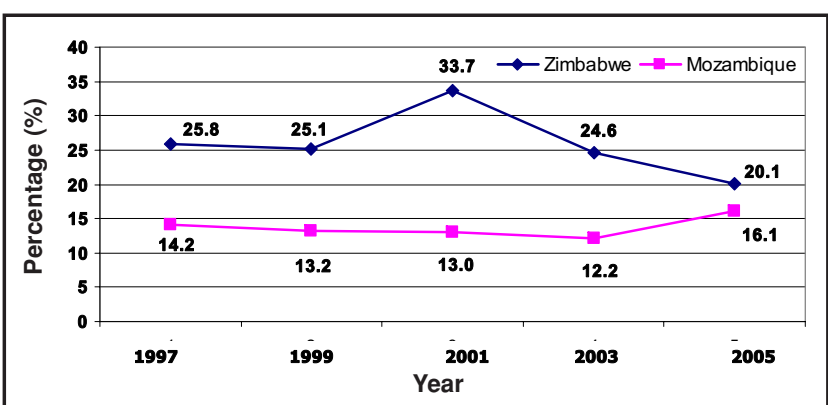

Figure 4 HIV prevalence among adults (aged 15-49 years), 1997-2005. Source: UNDP Human Development Reports for $2000^{39}, 2001^{40}, 2002^{41}, 2004^{42}$ and $2006^{19}$ 


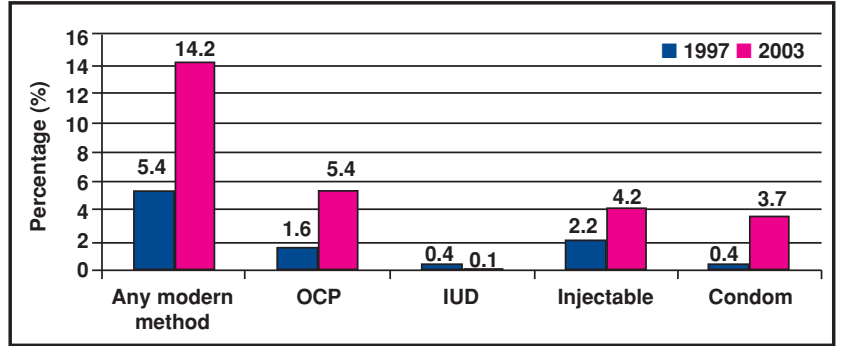

Figure 5 Current use of contraceptive methods in Mozambique, 1997-2003. Source: Demographic Health Surveys for Mozambique199827, 200531 (Macro International Inc.). OCP, oral contraceptive pill; IUD, intrauterine device

contraceptive usage. Condom use, although also growing, has remained low. Today, only $13 \%$ of females report having ever used a male condom. Actual usage of modern methods paints a similar picture with much lower prevalence (Figure 3). ${ }^{34}$ Use of OCP has been stable from 1988 (24\%) to 2005-2006 (27\%) with only a slight increase. Use of injectables has vastly increased from less than $1 \%$ in 1988 to $7 \%$ in 2005-2006. ${ }^{34,36}$ The percentage of women who are actually using condoms, however, has not seen such a dramatic increase. From 1994 to 2005-2006, condom use rate for married and all women in Zimbabwe was low at around $2 \% .34,37,38$ Furthermore, the vast majority of women using condoms are currently unmarried (26\%), whereas most women who use OCP are married $(43 \%) .{ }^{34}$ This is significant when individuals who are at greatest risk for HIV in a generalised epidemic are married.

With regard to the HIV epidemic in Zimbabwe, the estimated adult prevalence (ages 15-49 years) of HIV has peaked and fallen dramatically (Figure 4). As of 2005, adult HIV prevalence was $20 \% .{ }^{19}$ In 1997 , HIV prevalence was $26 \%$, increasing substantially to $34 \%$ in 2001 and finally dropping to $25 \%$ in $2003 .{ }^{39-42}$ The nation's major urban areas of Harare, Bulawayo and Chitungwiza experienced a considerable increase in HIV prevalence among antenatal clinic (ANC) clients from $10 \%$ in 1989 to $30 \%$ in 1995-2002. ${ }^{43}$ Furthermore, it is among STI clinic patients that HIV infection has been the highest. In Harare, HIV prevalence among clientele increased from 52\% in 1990 to $71 \%$ in 1995 and back to $53 \%$ in 1996.43

In Mozambique, 1997 and 2003 show a sharp increase in actual use of all modern methods, from $5 \%$ to $14 \%$, as well as ever use, from $13 \%$ to $47 \%$. Actual use of modern methods indicates that OCP and condoms exhibit the largest increase in contraceptive prevalence (2\% to $5 \%$ and $<1 \%$ to $4 \%$, respectively) (Figure 5). Ever use of modern methods exhibits a similar trend, where OCP ever use increased from $8 \%$ to $17 \%$, injectable ever use from $5 \%$ to $13 \%$ and condom ever use from $3 \%$ to $11 \% .^{27,31}$ The evidence here and discussion above suggest that a large percentage of FP goals are being met by HIV prevention programmes which have focused largely on unmarried individuals. As expected, modern contraceptive use by unmarried, sexually active women contributes greatly to contraceptive prevalence throughout the nation (compare $41 \%$ among unmarried sexually active women to $12 \%$ among married women in 2003). Furthermore, condom use among this group has followed a similar trend, where $20 \%$ of unmarried women and only $1 \%$ of married women reported using condoms in 2003. Age is also a large determinant of actual condom use. ${ }^{31}$ Although Mozambique has no formal policy addressing adolescents and HIV education, a study in 2001 which surveyed adolescents aged 15-24 years, found that $77.4 \%$ of males and $79.7 \%$ of females had been $\leq 17$ years of age at first intercourse. ${ }^{32,44}$ According to the 2003 DHS, young women from the same age group are more likely to report using condoms than women older than 24 years (15\% vs $6 \%$, respectively). ${ }^{27,31}$

At the beginning of sentinel surveillance in 1988 only $1 \%$ of ANC clientele in Mozambique were reported as HIV-positive. However, by 2002, $18 \%$ of clientele were found to be infected. In major urban areas, HIV infection follows the same trend. Outside of major urban areas, HIV prevalence has ranged from $11 \%$ in 1994 to $13 \%$ in 2002 . As expected, STI clinic patients are more likely to test positive for HIV. In 1999, HIV infection prevalence ranged from $22 \%$ to $50 \%$ outside of major urban areas. ${ }^{45}$ Overall, HIV prevalence among adults (aged 15-49 years) had been slowly decreasing until recently (Figure 4). In 1997, adult HIV prevalence was $14 \%$, hovering around $13 \%$ between 1999 and 2001, and dropping slightly to $12 \%$ in 2003. ${ }^{39-42}$ However, the number of adults infected with HIV rose sharply to $16 \%$ in 2005.19

\section{Discussion}

Although contraceptive prevalence in both case countries has increased, condom use has stalled in Zimbabwe and overall contraceptive prevalence is still low in Mozambique. Overall, FP programme effort has been very different in the two nations. Where Zimbabwe's programme efforts were once very strong but now are moderate, Mozambique's are considered very weak, but have significantly improved from being almost nonexistent 20 years ago. HIV/AIDS efforts decreased in Zimbabwe and increased in Mozambique. This is significant for other nations in similar settings as they show the potential for improvement given an integrated policy and programme effort.

Blanc and Tsui write: "The fundamental role of sexual activity for both conception and infection risk cannot be underestimated". 46 Countries which have been able to integrate FP and HIV counselling and testing services have found that they are able to reach otherwise inaccessible clients. For example, Uganda's AIDS Information Center is now able to meet the contraceptive needs of patients who would not normally visit a FP centre, such as men or sexually active adolescents. ${ }^{47}$ Cleland and Watkins write: "The promotion and availability of family planning ... represents one of the most significant public health success stories of the past century". 48 Yet HIV/AIDS policies continue to remain segregated from FP service delivery. Whereas HIV/AIDS prevention programmes tend to focus on single-use guidelines, FP clinics stress the need for contraception without discussing infection prevention. ${ }^{8}$

Until another more promising method of dual protection is commercially available (e.g. microbicides), condoms represent the most effective means to achieve the dual aims of reduction in HIV infection and unwanted pregnancy. But no form of prevention should place women in a vulnerable position. In 2006, Bill Gates declared, in contrast to US policy: "We need to put the power to prevent HIV in the hands of women ... No matter where she lives or what she does, a woman should never need her partner's permission to save her own life". 49 This is true for both HIV and safe motherhood. Although Gates speaks somewhat against the promotion of male condoms, the authors of this paper agree that efforts to prevent HIV and unwanted pregnancies must acknowledge the stigma and sex inequality deeply connected with condom negotiation. Furthermore, we agree that efforts must encompass methods which will give women all of their available options so that they can make informed decisions with respect to their own lives. 
In terms of condom promotion, however, it has been shown that women and men will share responsibility for using condoms. In a qualitative study done in Kampala, Uganda, couples who were already using condoms were asked how they agreed to do so. Women used insistence, refusal to have sex, persuasion, and need for birth control for self or to protect children as ways to convince their husbands to use a condom. Their tactics were helpful as they did not put any emphasis on distrust or infidelity within the relationship. The men were asked why they had accepted the method. Their reasons included to please their partner, protect her from HIV, protect their children, protect themselves, and to continue having outside partners. ${ }^{50} \mathrm{As}$ expected, further evidence also shows that it is easier to negotiate condom use for pregnancy prevention than for HIV/STI protection. ${ }^{51}$

In addition to condom promotion, mixing methods must be encouraged. Similar to the harm reduction model theory in that every bit of protection is considered significant, researchers agree that protection begins at near zero and increases with every effort made by the individuals. Therefore, each added method increases the protection a woman is receiving against HIV/STIs and pregnancy. ${ }^{17}$ Studies have shown that when informing women of all of their possible options for HIV/STI and pregnancy prevention, women will choose the highest level of protection possible in their circumstances. 8,24 Such a model is necessary in future policies addressing HIV and FP services. Thus, condoms should be encouraged and in combination with another contraceptive method, including $\mathrm{OCP}$, injectables and the intrauterine device, to provide the most protection possible. The report by Stratchan and colleagues, examining the integration of FP services in HIV protocols in 16 countries, states: "At the operational level, service delivery guidelines, protocols and tools are needed to address explicitly how FP can be integrated into new or existing services while ensuring that adequate support, including human and financial resources are available to make integration work." 8

Although further studies are warranted, the evidence suggests that countries with high HIV prevalence would benefit from efficiencies in a common FP and HIV strategy. As discussed earlier, FP policies in Zimbabwe have successfully increased demand for and use of hormonal FP methods, but the same policies may be interfering with the promotion of barrier methods for prevention of sexually transmitted HIV. It is now time for the Zimbabwean FP programme to promote the concept of dual protection, especially among those populations it is missing: single, sexually active adolescents as well as married couples.

In Mozambique, policies and guidelines are in place for the integration of both programmes, and the available results are pointing in the right direction. However, rising condom use is mostly due to the HIV programme rather than FP efforts. Thus to further increase use of barrier methods and the overall contraceptive prevalence, especially within vulnerable populations (i.e. rural women, young adults), the Mozambican FP programme should also focus on dual-use policies and the connection between FP and HIV services.

Furthermore, condom promotion via social marketing campaigns in both nations should avoid messages that condoms are primarily meant for disease protection, and PMTCT efforts should focus on meeting the unmet need for FP among HIV-positive women.

The financial resources of lesser-developed countries are not sufficient to cover all of the problems faced by their health systems. These countries lack the required capacity to mobilise commitment in the international community. If international priorities, including funding and guidance, continue as they do today, the needs of those who are at most risk will continue to be unmet. Countries such as Zimbabwe and Mozambique will continue to struggle in their efforts to address HIV/AIDS as well as the unmet need for FP. Governments in similar positions as those of our case countries rely on the powers of international bodies. If priorities are not rewritten, it will be a long time before significant improvement in population health outcomes will be seen. It is therefore imperative that policies and funding reassume the role of assisting the poor with FP services even in the light of the HIV epidemic.

\section{Statements on funding and competing interests \\ Funding None identified.}

Competing interests None identified.

\section{References}

1 Epstein H. The Invisible Cure: Africa, the West, and the Fight Against AIDS. New York, NY: Viking Books, 2007.

2 Joint United Nations Programme on HIV/AIDS (UNAIDS). 2006 Report on the Global AIDS Epidemic: A UNAIDS 10th Anniversary Special Edition. Geneva, Switzerland: UNAIDS, 2006; Executive Summary, 1-28.

3 Joint United Nations Programme on HIV/AIDS (UNAIDS). 2006 Report on the Global AIDS Epidemic: A UNAIDS 10th Anniversary Special Edition. Geneva, Switzerland: UNAIDS, 2006; Annex 2: HIV/AIDS estimates and data, 2005, 501-540.

4 Prata N. The need for family planning. Popul Environ 2007; 28: 212-222.

5 United Nations Population Fund (UNFPA). Reducing Risks by Offering Contraceptive Services. http://www.unfpa.org/ mothers/contraceptive.htm [Accessed 10 October 2007].

6 Reynolds HW, Janowitz B, Homan R, Johnson L. The value of contraception to prevent perinatal HIV transmission. Sex Transm Dis 2006; 33: 350-356.

7 United States Agency for International Development. Adding Family Planning to PMTCT Sites Increases the Benefits of PMTCT. Issue Brief. Washington, DC: United States Agency for International Development, July 2006.

8 Strachan M, Kwateng-Addo A, Hardee K, Subramaniam S, Judice N, Agarwal K. An Analysis of Family Planning Content in HIVIAIDS, VCT, and PMTCT Policies in 16 Countries (Working Paper Series No. 9). Washington, DC: POLICY Project, 2004.

9 Mayhew SH, Walt G, Lush L, Cleland J. Donor agencies' involvement in reproductive health: saying one thing and doing another. Int J Health Serv 2005; 35: 579-601.

10 Ross J. Family Planning Programs in the Context of the HIV Crisis, With Reference Also to Maternal Health Programs. Washington, DC: The Futures Group, POLICY Project, 2002.

11 USAID, UNAIDS, POLICY Project. Measuring the Level of Effort in the National and International Response to HIVIAIDS: The AIDS Programme Effort Index (API) Summary Report. Washington, DC: UNAIDS, 2001.

12 Ross JA, Stover J. Family planning programs in 2004: new assessments in changing environment. Int Fam Plann Perspect 2007; 33: 22-30.

13 Ali MM, Cleland J, Shah I. Condom use within marriage: a neglected HIV intervention. Bull World Health Organ 2004; 82 180-186.

14 Chaya N, Amen K, Fox M. Condoms Count; Meeting the Need in the Era of HIVIAIDS. The PAI Report Card 2002. Washington, DC: Population Action International, 2002.

15 United Nations Population Fund (UNFPA). State of the World Population 2004; The Cairo Consensus at Ten: Population, Reproductive Health and the Global Effort to End Poverty. New York, NY: UNFPA, 2004

16 Shah I. Contraceptive use patterns in countries with different levels of HIV epidemic. J AIDS 2005; 38(Suppl. 1): S5-S6.

17 Gollub EL. Choice is empowering: getting strategic about preventing HIV infection in women. Int Fam Plann Perspect 2006; 32: 209-212.

18 Population Reference Bureau. DataFinder: Search Population and Health Data. http://www.prb.org/DataFind/datafinder7.htm [Accessed 12 October 2007].

19 United Nations Development Programme (UNDP). Human Development Report 2006; Beyond Scarcity: Power, Poverty and the Global Water Crisis. New York, NY: UNDP, 2006.

20 United Nations Population Fund (UNDP). Financial Resource Flows for Population Activities in 2004. New York, NY: UNDP, 2004.

21 United Nations Population Fund (UNFPA). Donor Support for Contraceptives and Condoms for STI/HIV Prevention 2005. New York, NY: UNFPA, 2005. 
22 United Nations Population Fund (UNFPA). Financial Resource Flows for Population Activities in 2002. New York, NY: UNFPA, 2002.

23 United Nations Population Fund (UNFPA). Donor Support for Contraceptives and Condoms for STI/HIV Prevention 2001. New York, NY: UNFPA, 2001.

24 Garbus L, Khumalo-Sakutukwa G. Country AIDS Policy Analysis Project; HIVIAIDS in Zimbabwe. San Francisco, CA: AIDS Policy Research Center, University of California, 2003.

25 Chaya N, Haddock S. 2006 Data Update; Condoms Count; Meeting the Need in the Era of HIVIAIDS. Washington, DC: Population Action International, 2006.

26 Maggwa BN, Askew I, Marangwanda C, Nyakauru R, Janowitz B; Zimbabwe National Family Planning Council, Family Health International. An Assessment of the Zimbabwe National Family Planning Council's Community Based Distribution Program. Washington, DC: Population Council, 2001.

27 Instituto Nacional de Estatistica and Ministerio da Saude and ORC Macro/DHS Program. Mocambique Inquerito Demografico e de Saude 1998. Calverton, MD: Macro International Inc., 1998.

28 International Planned Parenthood Federation. Country Profile: Mozambique. http://www.ippf.org/en/Where/country.htm? country=MZ [Accessed 12 October 2007].

29 The Carter Center. In Focus: Development Planning in Mozambique. http://www.cartercenter.org/news/documents/ doc1313.html [Accessed 18 October 2007].

30 The Carter Center. Activities by Country: Mozambique. http://www.cartercenter.org/countries/mozambique.html [Accessed 18 October 2007].

31 Instituto Nacional de Estatistica and Ministerio da Saude and ORC Macro/DHS Program. Mocambique Inquerito Demografico e de Saude 2003. Calverton, MD: Macro International Inc., 2005.

32 United Nations General Assembly Special Session. Government of Mozambique UNGASS Declaration of Commitment on HIV/AIDS; Progress Report; Reporting Period 2003-2005 (Draft version 1.4). Geneva, Switzerland: UNAIDS, 2006.

33 Best K. Family Planning and the Prevention of Mother-to-Child Transmission of HIV; A Review of the Literature. Research Triangle Park, NC: Family Health International, 2004.

34 Central Statistical Office Harare, Zimbabwe and Macro International Inc. Zimbabwe: Standard DHS, 2005/06. Calverton, MD: Macro International Inc., 2005-2006.

35 Ross J, Stover J. The Family Planning Program Effort Index: 1999 Cycle. Int Fam Plann Perspect 2001; 27: 119-129.
36 Central Statistical Office Ministry of Finance, Economic Planning and Development Zimbabwe and DHS Macro Systems, Inc. Zimbabwe Demographic and Health Survey 1988. Calverton, MD: Macro International Inc., 1989.

37 Central Statistical Office Zimbabwe and DHS Macro International Inc. Zimbabwe Demographic and Health Survey 1994. Calverton, MD: Macro International Inc., 1995.

38 Central Statistical Office Zimbabwe and MEASURE DHS+ Macro International Inc. Zimbabwe Demographic and Health Survey 1999. Calverton, MD: Macro International Inc., 2000.

39 United Nations Development Programme (UNDP). Human Development Report 2000: Human Rights and Human Development. New York, NY: UNDP, 2000.

40 United Nations Development Programme (UNDP). Human Development Report 2001: Making New Technologies Work for Human Development. New York, NY: UNDP, 2001

41 United Nations Development Programme (UNDP). Human Development Report 2002: Deepening Democracy in a Fragmented World. New York, NY: UNDP, 2002

42 United Nations Development Programme (UNDP). Human Development Report 2004: Cultural Liberty in Today's Diverse World. New York, NY: UNDP, 2004.

43 UNAIDS, UNICEF, WHO. Epidemiological Fact Sheets on HIVIAIDS and Sexually Transmitted Infections Zimbabwe, 2004 Update. Geneva, Switzerland: UNAIDS, 2004

44 Prata N, Morris L, Mazive E, Vahidnia F, Stehr M. Relationship between HIV risk perception and condom use: evidence from a population-based survey in Mozambique. Int Fam Plann Perspect 2006; 32: 192-200.

45 UNAIDS, UNICEF, WHO. Epidemiological Fact Sheets on HIVIAIDS and Sexually Transmitted Infections Mozambique, 2004 Update. Geneva, Switzerland: UNAIDS, 2004

46 Blanc A, Tsui A. The dilemma of past success: insiders' views on the future of the international family planning movement. Stud Fam Plann 2005; 36: 263-276.

47 INFO REPORTS. Focus on ... Integrating Family Planning and HIVIAIDS Services: A Digest of Key Resources. Baltimore, MD: The INFO Project, 2006(6); 1-20.

48 Cleland J, Watkins S. The key lesson of family planning programmes for HIV/AIDS control. AIDS 2006; 20: 1-3.

49 Glasier A. Putting sexual and reproductive health on the agenda. Lancet 2006; 368: 1550-1551.

50 Williamson N, Liku J, McLoughlin K, Nyamongo I, Nakayima F. A qualitative study of condom use among married couples in Kampala, Uganda. Reprod Health Matters 2006; 14: 89-98.

51 Smith DJ. Premarital sex, procreation, and HIV risk in Nigeria. Stud Fam Plann 2004; 35: 223-235.

\section{BOOK REVIEWS}

The Hot Flush Diary: Take Control of Your Menopause. Susan Kelsey, Russell Kelsey. Worcester, UK: Susan Russell Publishing, 2007. ISBN-13: 978-0-955-63090-3. Price: $£ 14.99$.

\section{Pages: 272 (hardback)}

It's a sobering thought that in the UK nearly 10 million women are perimenopausal or postmenopausal. With the gathering suspicion that I might very soon be joining their ranks (since the average woman will encounter the menopause at the age of 51 years) and, as the saying goes: "forewarned is forearmed", I embarked on the task of reviewing The Hot Flush Diary with a mixture of emotions

The diary starts with a section of (necessarily brief) background information on the (peri)menopause, covering topics such as common symptoms, conventional and alternative therapies, risks associated with HRT use, dietary factors, and the importance of talking to family and friends about how you feel (which, for many, is still a taboo subject). Whilst this section of the diary is useful, many women will wish to supplement the information it contains by reading some of the many books available on this topic and/or by referring to websites such as www.menopausematters.co.uk.

Detailed instructions on how to use the diary are followed by pages on which key life events, diet, exercise, interventions and emotions are documented on a week-by-week basis, and a pullout chart on which various symptoms (eg, bleeding, hot flushes, night sweats, etc.) are recorded daily, which together form a comprehensive record of 12 months in the life of a peri(menopausal) woman.

The diary is attractively designed, discreet, and easy to use. Whether a woman would buy or use The Hot Flush Diary does of course depend on whether the idea of keeping such a diary appeals to the individual concerned. If completed diligently, this diary will allow a woman to track the myriad symptoms of her peri(menopause) and, should she subsequently wish to seek advice from a health professional, the visual record of key symptoms may facilitate a diagnosis and subsequent treatment plan. Another perceived benefit offered by this diary for some users will be the means of gaining some measure of control during a life phase that many women find irksome and (in some cases) distressing.

Sales of The Hot Flush Diary should be good, not just because of the size of the potential market, but also because typically the menopause can last from 2-5 years and so keen diarists may well wish to purchase multiple copies!

\section{Reviewed by Janie Foote, BSc}

Editorial Manager, Journal of Family Planning and Reproductive Health Care

The First Moon Diary: Taking Control of Your First Menstrual Cycles. Susan Kelsey, Russell Kelsey. Worcester, UK: Susan Russell Publishing, 2007. ISBN-13: 978-0-955-63091-0. Price: $£ 14.99$. Pages: 272 (hardback)

This is one of a range of symptom-monitoring diaries designed to "help patients take control of their medical symptoms". This particular diary is aimed at girls just starting their periods.

The diary consists of 40 pages of information and advice followed by over 200 pages of structured diary for recording emotions, plans, exercise, diet, life events and menstrual bleeding. The information section has reasonably sensible, accessible sections on the various trials and tribulations of puberty.

I shared this book with a young teenager who felt that overall it was informative and could be very useful to some people. Advice on healthy eating just repeated what she's learnt "every year at school" and rather put her off. Some of the information about sanitary protection and vaginal discharges was dismissed as "sick" and she also felt people might worry that all the "bad things" would happen to them.

My first (selfish) feeling was weariness at the thought of a 13-year-old entering my consulting room with 200 pages of completed First Moon Diary entries. One wonders how sensible it is to encourage girls to focus and ruminate on normal physiological changes.

Overall, I agree with my teenage friend that much of the information was superfluous for most teenagers but that the principle was good and a few youngsters would find it helpful. I just hope they do not feel the need to share their completed diaries with me.

Reviewed by Kate Weaver, MBChB, MFSRH Staff Grade Doctor, Dean Terrace Family Planning Clinic, Edinburgh, UK 